\title{
Endothelial Progenitor Cell Levels and Extent of Post-prandial Lipemic Response
}

\author{
Buket Akcan ${ }^{1 \star t}$, Asim Örem $^{2 \dagger}$, Yahya Altinkaynak ${ }^{3}$, Birgül Kural ${ }^{2}$, Cihan Örem ${ }^{4}$, \\ Mehmet Sönmez ${ }^{5}$ and Mauro Serafini ${ }^{6}$
}

${ }^{1}$ Department of Nutrition and Dietetics, Faculty of Health, Ardahan University, Ardahan, Turkey, ${ }^{2}$ Department of Medical Biochemistry, Faculty of Medicine, Karadeniz Technical University, Trabzon, Turkey, ${ }^{3}$ Department of Medical Services and Techniques, Ardahan Vocational School of Health Services, Ardahan University, Ardahan, Turkey, ${ }^{4}$ Department of Cardiology, Faculty of Medicine, Karadeniz Technical University, Trabzon, Turkey, ${ }^{5}$ Department of Hematology, Faculty of Medicine, Karadeniz Technical University, Trabzon, Turkey, ${ }^{6}$ Functional Food and Metabolic Stress Prevention Laboratory, Teramo University, Teramo, Italy

OPEN ACCESS

Edited by:

Thea Magrone,

University of Bari Aldo Moro, Italy

Reviewed by:

Min Wu,

China Academy of Chinese Medical

Sciences, China

Monica Dinu,

Università degli Studi di Firenze, Italy Lorenzo Romano,

University of Rome Tor Vergata, Italy

${ }^{*}$ Correspondence:

Buket Akcan

buketakcan@ardahan.edu.tr

tThese authors have contributed equally to this work and share first

authorship

Specialty section:

This article was submitted to

Nutritional Epidemiology,

a section of the journal

Frontiers in Nutrition

Received: 25 November 2021

Accepted: 07 January 2022

Published: 14 February 2022

Citation:

Akcan B, Örem A, Altinkaynak Y, Kural B, Örem C, Sönmez M and

Serafini M (2022) Endothelial

Progenitor Cell Levels and Extent of

Post-prandial Lipemic Response.

Front. Nutr. 9:822131.

doi: 10.3389/fnut.2022.822131
Background and Objective: Due to the frequency of meal ingestion, individuals spend the majority of the day, $\sim 18 \mathrm{~h}$, in a status of post-prandial (PP) stress. Remnant-like lipoprotein particles (RLPS) are predominant in PP phase playing an important role in the development of atherosclerosis. Endothelial progenitor cells (EPCs) have been suggested to play a role in vessel wall homeostasis and in reducing atherosclerosis. However, there is no information about peripheral blood EPCs number following PP stress. We investigated the association between circulating EPCs levels and extent of PP lipemia in healthy subjects following a high-fat meal.

Materials and Methods: A total of 84 healthy subjects (42 men, 42 women) aged 17-55 years were included in the study. PP lipemic response of subjects was determined by Oral Fat-Loading Test (OFLT). All the subjects were classified on the basis of their plasma TG levels after PP lipemic stressors in categories 1 (low), 2 (moderate), and 3 (high). Circulating EPCs numbers were measured by the flow cytometry method.

Results: There was a significant difference in terms of lipid parameters between men and women: high-density lipoprotein cholesterol (HDL-C) was significantly lower in men than in women $(p<0.001)$. Total cholesterol (TC) $(p=0.004)$, low-density lipoprotein cholesterol (LDL-C) $(p<0.001)$, triglyceride (TG) $(p<0.001)$, and TG-AUC $(p<0.001)$ were significantly higher in men than in women. There was no significant difference between the genders in terms of $\mathrm{CD} 34^{+} \mathrm{KDR}^{+}$and $\mathrm{CD} 34^{+} \mathrm{KDR}^{+} \mathrm{CD} 133^{+}$cell number and MMP-9 levels. Vascular endothelial growth factor (VEGF) levels were significantly higher in men than women $(p=0.004)$. TC, LDL-C, and TG were significantly higher in the 3rd category than 1st and 2 nd categories $(p<0.001)$ in women. Age, body mass index (BMI), fat rate, TG, TC, and LDL-C were significantly higher in the 3rd category than 1st category $(p<0.001, p=0.002, p=0.002, p=0.01, p=$ $0.007, p=0.004$; respectively), in men. Circulating numbers of EPCs in men were significantly higher in the PP hyperlipidemia group than in the low TG levels category, independently from age $(p<0.05)$. Circulating EPC levels showed a positive correlation 
with OFLT response in men $(r=0.414, p<0.05)$. Also, OFLT response showed a strong positive correlation with fasting TG levels $(r=0.930, p<0.001)$. EPC levels in categories of women were not different.

Conclusion: Increased EPCs levels in subjects with different PP hyperlipidemia may be associated with a response to endothelial injury, related to increased atherogenic remnant particles at the PP phase.

Keywords: atherosclerosis, endothelial injury, remnant-like lipoproteins, high fat diet, hyperlipidemia

\section{INTRODUCTION}

Atherosclerotic cardiovascular disease (CVD) is one of the leading causes of death worldwide. Epidemiological studies in recent years have shown that hypertriglyceridemia is an independent risk factor for CVDs. In a meta-analysis of 17 prospective studies involving 46.413 men and 10.864 women, Hokanson and Austin emphasized that subjects with a fasting triglycerides (TGs) level higher than $89 \mathrm{mg} / \mathrm{dl}$ had a $14 \%$ greater risk for CVDs (1). Studies have shown that hypertriglyceridemia is associated with atherosclerosis, but the independence of the serum TG concentration as a causal factor in promoting CVDs is still an object of scientific debate (2-5). Plasma concentrations of TG after a stressor meal seem to be better indicator with respect to fasting TG for predicting $\operatorname{CVD}(6,7)$. Due to the frequency of meal ingestion, individuals spend the majority of the day, $\sim 18 \mathrm{~h}$, in the post-prandial (PP) phase. Remnant-like lipoprotein particles (RLPs) are predominant in the PP phase and they play an important role in the development of atherosclerosis. Many studies have revealed that TG-rich lipoproteins (TRL), especially chylomicron and very LDL (VLDL) remnants, are atherogenic and that delayed removal of chylomicron remnants from the bloodstream induces PP hyperlipidemia (8-10).

Endothelial dysfunction is known to be an early event in atherosclerosis and an important contributor to the pathogenesis of coronary artery disease. The endothelium can repair itself. Cells with the ability to repair the endothelium have been termed endothelial progenitor cells (EPCs). Studies on the molecular mechanisms of atherosclerosis development have emphasized that EPCs may have a very important role in vessel wall homeostasis and in reducing atherosclerosis. Accordingly, the "response to injury" hypothesis of atherosclerosis has been proposed as "EPC-mediated repair of injury" $(11,12)$. Hill et al. showed a strong correlation between the number of EPCs in peripheral blood and patients with Framingham risk factor scores (13). Studies conducted in the last decade have shown that repair of damaged endothelium occurs not only with cells in that region, but also with contributions from circulating EPCs. EPCs originate from the bone marrow and are released into the circulation under the influence of growth factors such as vascular endothelial growth factor (VEGF) secreted by stimulants such as tissue ischemia (14-16). Various drugs and factors such as exercise also stimulate the circulating release of EPCs. Circulating EPCs adhere to the damaged area and mature in the damaged endothelial area with the effect of adhesion molecules and cytokines (17-19). The balance between the development of endothelial damage in the area of the damaged atherosclerotic lesion and the endothelial repair process determines the outcome of the atherosclerotic lesion. Lack of EPC number and function is associated with the accelerated development of atherosclerosis in these damaged areas. It is seen that almost all the classical risk factors that cause the development of atherosclerosis have negative effects on the number and function of EPC. Many studies have shown that there is an inverse relationship between advanced age, hypertension, diabetes mellitus, smoking and oxidative stress, and the number and functions of EPC (20).

It is known that the TG-rich remnant lipoproteins responsible for the PP hyperlipidemia, cause endothelial damage leading to atherosclerosis. The idea that remnant lipoproteins could induce atherosclerosis by accelerating EPC aging was first suggested by $\mathrm{Pu}$ and Ling (21), and then Liu et al. showed that it reduces the proliferation capacity (22). There is no information in the literature about the peripheral blood EPCs number in PP lipidemia. Since people with PP hypertriglyceridemia spend most of their lives and days with high blood atherogenic remnant lipoprotein particles, it is likely to have adverse effects on EPC synthesis and secretion from the bone marrow, and also other risk factors. As it is known that EPCs play a role in repairing endothelial damage it is also possible that remnant lipoproteins are effective on EPCs, their structure, and function $(23,24)$.

In this study, we investigated the association between circulating EPCs levels and the extent of PP lipemia in healthy subjects following a high-fat meal.

\section{MATERIALS AND METHODS}

\section{Subjects}

A total of 84 healthy subjects (42 men, 42 women) aged 17-55 years were included in this study. Health status of the subjects was evaluated by means of detailed medical history, physical examinations, and laboratory tests of blood samples [complete blood cell count (CBC), lipids, lipoproteins, and thyroid function tests including TSH, free-T4, liver, and kidney function tests] at the Karadeniz Technical University Farabi Hospital. Exclusion criteria included smoking status, alcohol or drug abuse, presence of acute and chronic inflammatory diseases, chronic kidney disease, obesity, and endocrine disorders related to lipid and lipoprotein metabolism, such as diabetes mellitus, menopause, estrogen replacement therapy, and thyroid hormone disorders. Subjects performing heavy exercise and those on the herbal medicines were also excluded. 


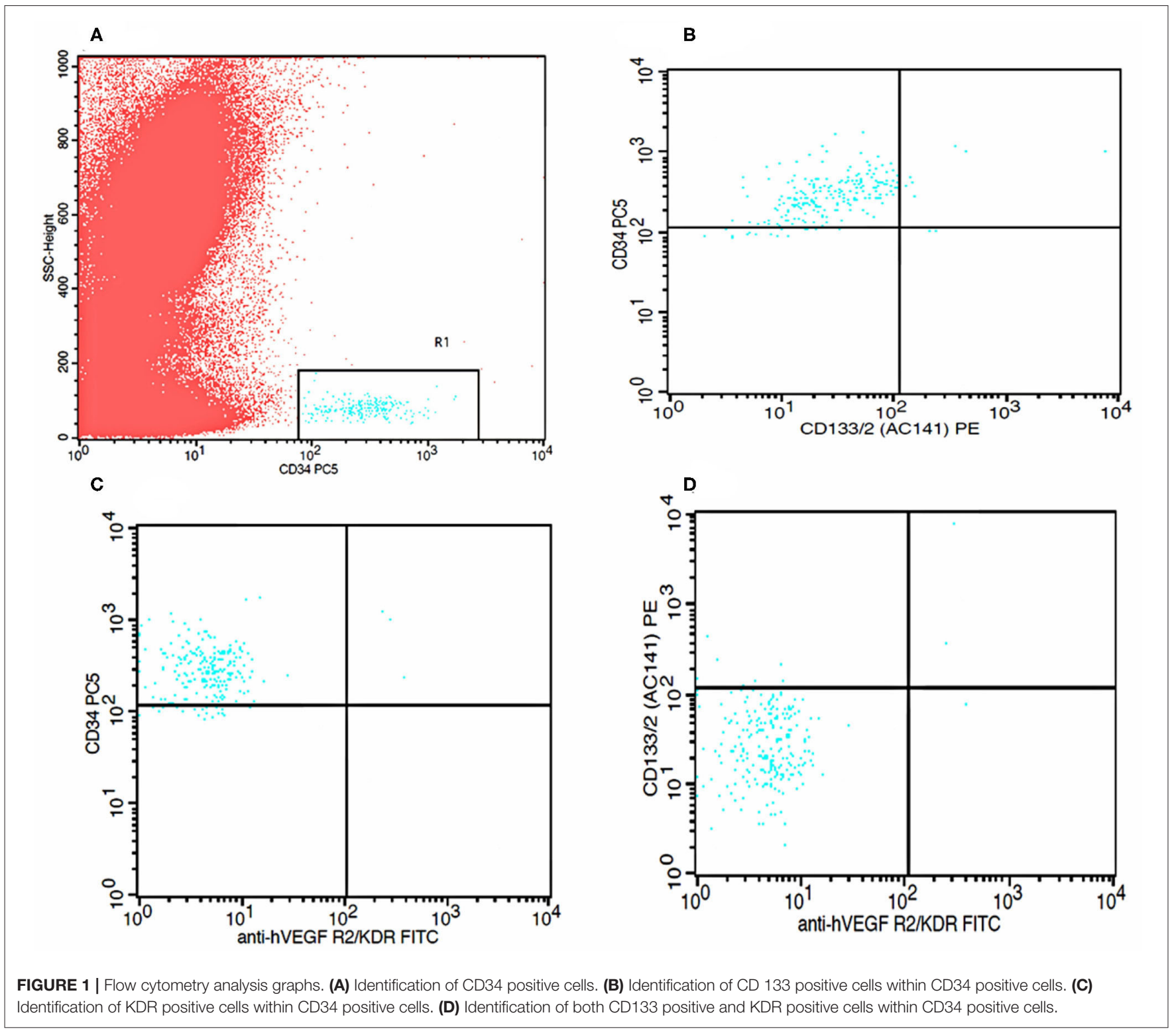

\section{Study Design}

This was an acute-randomized dietary intervention trial. At inclusion, a fasting blood sample was obtained and anthropometric measurements were performed. Body weights $(\mathrm{kg})$, body fat percentages, body mass index (BMI) were obtained using impedance scales (Tanita Body Composition Analyzer, TBF-300, Illinois, USA). BMI was calculated using the formula weight $/$ height ${ }^{2}\left(\mathrm{~kg} / \mathrm{m}^{2}\right)$. The waist-to-hip ratio was calculated by measuring the circumferences at the waist (midway between the rib cage and iliac crest) and hip (maximal circumference between the iliac crest and thigh region). After this stage, OFLT was administered to the subjects and blood sampling was obtained at 2nd, 4th, and 6th $\mathrm{h}$ in PP phase. OFLT was performed according to the Cortes and Patsch methods with some changes $(25,26)$. Fat meal for OFLT was a toast with cheese and butter and as a drink ayran. Ayran is a traditional Turkish beverage made from yogurt or milk and contains carbohydrates, fat, protein, and calcium. The fat meal was containing $24.1 \%$ carbohydrate, $62.5 \%$ fat, and $13.4 \%$ protein representing a total energy content of 1,100 $\mathrm{kcal}$. Subjects were rested for $30 \mathrm{~min}$ before the administration of the fat load and then were consumed a fat meal with ayran. Peripheral blood samples were obtained in sodium EDTA coated, sodium citrate coated, and without anticoagulant gelled tubes. Samples were kept on ice and centrifuged immediately for $15 \mathrm{~min}$ at $3,000 \mathrm{rpm}$ at $4^{\circ} \mathrm{C}$; then, plasma and serum were stored at $-80^{\circ} \mathrm{C}$ until assayed. Blood samples were obtained from subjects daily for analysis of the numbers of EPCs.

The area under the curve (AUC), from fasting TG levels and at 2,4 , and $6 \mathrm{~h}$ from OFLT, was obtained value was calculated with the following formula according to the trapezoidal rule. TG-AUC $=\mathrm{TG}$ fasting $(\mathrm{mg} / \mathrm{dl})+2 \times[\mathrm{TG}$ PP $2 \mathrm{nd} \mathrm{h} .(\mathrm{mg} / \mathrm{dl})+\mathrm{TG}$ PP 4 th h. $(\mathrm{mg} / \mathrm{dl})]+$ TG 4 th h. $(\mathrm{mg} / \mathrm{dl})$. 
The study protocol was approved by the local research ethics committee of the Karadeniz Technical University Farabi Hospital (file number: 2010/72-13). All the participants gave written informed consent. The study was conducted according to the recommendations of the Declaration of Helsinki.

\section{Biochemical Determinations Lipid Analysis}

Serum lipid levels were measured enzymatically. TC, HDL$\mathrm{C}$, and LDL-C levels measured in fasting serum samples, Triglyceride (TG) levels measured in fasting and PP 2nd, 4th, and 6th h serum samples by enzymatic colorimetric method with auto analyzer (Roche Cobas 8000, Modular Clinical Chemistry, GmbH, Mannheim, Germany).

Determination of Circulating EPCs by Flow Cytometry The number of EPCs was determined by flow cytometry (FACS Calibur, Becton Dickinson, Heidelberg, Germany); briefly, $100 \mu \mathrm{l}$ whole blood in cubated with fluorochrome-labeled antibodies to CD133 mAB-PE (Miltenyi Biotec,Bergisch Gladbach, Germany), CD34 mAB-PC (Beckman Coulter, Indianapolis, IN, USA), and VEGFR2/KDR-FITC (R\&D System, Minneapolis, MN, USA) antibodies at room temperature for 10 minutes. After red cell lysis, the samples were washed and incubated with FITC and $\mathrm{PE}$ at room temperature for $15 \mathrm{~min}$. For analysis, first CD34 or CD133 positive cells were gated, identified as a distinct cell population with high expression of the antigens mentioned earlier and low-side scatter, and then these cells were assayed for KDR expression in the mononuclear cell fraction (Figure 1). Cells that were $\mathrm{CD} 34^{+} \mathrm{KDR}^{+}$(late EPCs) and $\mathrm{CD} 34^{+} \mathrm{CD} 133^{+} \mathrm{KDR}^{+}$(early EPCs) were considered EPCs. $\mathrm{CD} 34^{+} \mathrm{CD} 133^{+}$cells were considered CECs. For all the analyses, $5 \times 10^{5}$ events were collected and scored using an FACS Calibur analyzer (Becton Dickinson). The data were processed using the Macintosh CELL Quest software package (Becton Dickinson), and the cell count was expressed per one million cytometric events.

\section{Enzyme-Linked Immunosorbent Assay}

Plasma VEGF and MMP-9 levels were measured using commercial ELISA kits according to the standard protocols of the manufacturer (R\&D System Quantikine Human VEGF Immunoassay, Lot: 291989, Catalog Number: DVE00 and R\&D System Quantikine Human MMP-9 Immunoassay, Lot: 291696, Catalog Number: DMP900 Minneapolis, MN, USA). The appropriate recombinant human VEGF was used for calibration. The sensitivity of the present assay for VEGF was $9 \mathrm{pg} / \mathrm{ml}$ and for MMP-9 was $0.156 \mathrm{ng} / \mathrm{ml}$.

\section{Statistical Analysis}

Data were given as mean and SD for normally distributed variables and median (interquartile range) for non-normally distributed variables. The distribution of variables was assessed by the Kolmogorov-Smirnov test. Comparison of two groups was performed using Student's $t$-test or Mann-Whitney $U$-test. Each sex group was categorized into three equal subgroups based on tertiles of TG-AUC values. Participants with low TG-AUC values were enrolled in Category 1, those with intermediate values in Category 2, and those with high values in Category 3. ANOVA and Kruskal-Wallis test were used to compare parameters among tertiles. Tukey's test was performed for post-hoc comparisons. Pearson or Spearman correlation analysis was used to assess the relationships between PP lipemia and atherogenic indices including lipids and lipoproteins and also EPC numbers in the light of the skewness of data distribution. $P<0.05$ was accepted as statistically significant. Statistical procedures were performed on SPSS for Windows version 16.0 (SPSS Incorporation, Chicago, Illinois, USA) software.

\section{RESULTS}

\section{Baseline Characteristics of The Study Population}

Physical characteristics, biochemical, and immunological parameters of the subjects are shown in Table 1. Men were overweight and older respect to women. There was a significant difference in terms of lipid parameters between men and women: HDL-C was significantly lower in men than in women $(p<$ $0.001)$. TC $(p=0.004)$, LDL-C $(p<0.001)$, TG $(p<0.001)$, and TG-AUC $(p<0.001)$ were significantly higher in men than women. There was no significant difference between the genders in terms of $\mathrm{CD} 34^{+} \mathrm{KDR}^{+}$and $\mathrm{CD} 34^{+} \mathrm{KDR}^{+} \mathrm{CD} 133^{+}$cell number and MMP-9 levels. VEGF levels were significantly higher in men than women $(p=0.004)$.

TABLE 1 | Physical characteristics and biochemical and immunological parameters of the subjects at baseline.

\begin{tabular}{lcccc}
\hline Parameters & $\begin{array}{c}\text { Total study } \\
\text { group }(\boldsymbol{n}=\mathbf{8 4})\end{array}$ & $\begin{array}{c}\text { Women } \\
(\boldsymbol{n}=\mathbf{4 2})\end{array}$ & Men $(\boldsymbol{n}=\mathbf{4 2})$ & $\boldsymbol{P}$ \\
\hline Age (years) & $30.4 \pm 11.0$ & $26.5 \pm 8.9$ & $34.4 \pm 11.6$ & 0.001 \\
BMl (kg/m $\left.{ }^{2}\right)$ & $25.7 \pm 4.8$ & $24.2 \pm 4.8$ & $27.2 \pm 4.2$ & 0.002 \\
TG-AUC & $916.7 \pm 476.0$ & $676.3 \pm 276.7$ & $1157.0 \pm$ & $<0.001$ \\
(mg/dL/hour) & & & 513.7 & \\
Waist/Hip & $0.8 \pm 0.09$ & $0.8 \pm 0.07$ & $0.9 \pm 0.06$ & $<0.001$ \\
Fat rate (\%) & $24.1 \pm 8.2$ & $26.9 \pm 8.8$ & $21.2 \pm 6.3$ & 0.001 \\
TG (mg/dL) & $95.5 \pm 51.2$ & $72.8 \pm 27.9$ & $118.1 \pm 58.9$ & $<0.001$ \\
TC (mg/dL) & $186.2 \pm 39.4$ & $174.1 \pm 27.9$ & $198.3 \pm 45.3$ & 0.004 \\
LDL-C (mg/dL) & $108.6 \pm 34.9$ & $93.0 \pm 21.5$ & $124.1 \pm 38.8$ & $<0.001$ \\
HDL-C & $53.6 \pm 13.4$ & $61.4 \pm 12.6$ & $45.9 \pm 9.1$ & $<0.001$ \\
(mg/dL) & & & & \\
CD34 ${ }^{+} \mathrm{KDR}^{+}$ & $2(1-3)$ & $2(1-3)$ & $1.5(1-4)$ & $0.634^{*}$ \\
CD34 ${ }^{+} \mathrm{KDR}^{+}$ & $2(0-3)$ & $2(0-3)$ & $1(0-4)$ & $0.943^{*}$ \\
CD133 & & & & \\
VEGF (pg/ml) & $55.4 \pm 22.4$ & $48.5 \pm 21.1$ & $62.3 \pm 21.9$ & 0.004 \\
MMP-9 (ng/ml) & $397.4 \pm 142.8$ & $377.9 \pm 118.5$ & $416.8 \pm 162.6$ & 0.214
\end{tabular}

$P$-values according to the Student's t-test. Data were expressed as mean $\pm S D$. ${ }^{*} P$-values according to the Mann-Whitney U-test. Data were expressed as median (interquartile range for $25-75 \%$ ).

$B M I$, body mass index; $A \cup C$, area under the curve; $C D 34^{+} K D R^{+}$, late endothelial progenitor cell; $C D 34^{+} K D R^{+} C D 133^{+}$, early endothelial progenitor cell. 


\section{Stratification by Tertiles of TG-AUC Levels}

Because TG-AUC levels were found significantly different between genders, women and men were divided separately into tertiles according to their TG-AUC levels and all outcomes were evaluated accordingly. Participants with low TG-AUC values were enrolled in Category 1, those with intermediate values in Category 2, and those with high values in Category 3 as described in Table 2.

There were no significant differences in terms of anthropometric values between the women's categories (Table 2). TC, LDL-C, and TG were significantly higher in the $3^{\text {rd }}$ category than $1^{\text {st }}$ and $2^{\text {nd }}$ categories $(p<0.001)$. TG was significantly higher in the $2^{\text {nd }}$ category than $1^{\text {st }}$ category $(p<0.001)$. Although HDL-C was higher in the $1^{\text {st }}$ category than other categories, no statistically significant differences were found between the categories. There were no significant differences between the categories in terms of $\mathrm{CD}^{3} 4^{+} \mathrm{KDR}^{+}$and $\mathrm{CD} 4^{+} \mathrm{KDR}^{+} \mathrm{CD} 133^{+}$cell number, VEGF, and MMP- 9 levels (Table 2).

There was a significant difference in terms of anthropometric values between the categories of men (Table 3). According to this, age, BMI, and fat rate were higher in the $3^{\text {rd }}$ category than $1^{\text {st }}$ category ( $p=0.01, p=0.007, p=0.004$; respectively). BMI and fat rate were higher in the $2^{\text {nd }}$ category than $1^{\text {st }}$ category. There were no significant differences in terms of waist/hip ratio between the categories. TG, TC, and LDL-C were significantly higher in the $3^{\text {rd }}$ category than $1^{\text {st }}$ category $(p<0.001, p=$ $0.002, p=0.002$; respectively). HDL-C was significantly lower in the $3^{\text {rd }}$ category than $1^{\text {st }}$ category $(p=0.039)$ LDL-C was highest in the $3^{\text {rd }}$ category and was significantly higher in the $2^{\text {nd }}$ category than $1^{\text {st }}$ category $(p=0.002)$ (Table 3 ). TG was also significantly higher in the $2^{\text {nd }}$ category than $1^{\text {st }}$ category $(p$ $<0.001) . \mathrm{CD} 4^{+} \mathrm{KDR}^{+}$and $\mathrm{CD} 34^{+} \mathrm{KDR}^{+} \mathrm{CD} 133^{+}$cell number were significantly higher in the $3^{\text {rd }}$ category than $1^{\text {st }}$ category ( $p=0.026, p=0.015$; respectively). There were no significant differences between the categories in terms of VEGF and MMP9 levels (Table 3). There was a strong correlation between TG-AUC and early EPC numbers $(p=0.006, r=0.414)$ (Figure 2).

\section{Effects of Age Differences}

Women and men were divided separately into two groups according to their ages. BMI, waist/hip ratio, fate rate, and LDL-C were significantly higher in the middle age than the young group in women $(p=0.016, p<0.001, p=0.018$, $p=0.034$; respectively) (Table 4). There were no statistically significant differences in terms of TG-AUC, TG, TC, HDL-C, $\mathrm{CD}_{3}{ }^{+} \mathrm{KDR}^{+}$, and $\mathrm{CD} 34^{+} \mathrm{KDR}^{+} \mathrm{CD} 133^{+}$cell number, MMP-9 and VEGF between the young and middle age groups.

Body mass index, TG-AUC, waist/hip ratio, fate rate, TG, TC, and LDL-C were significantly higher in the middle age than the young group ( $p=0.007, p=0.001, p=0.002, p=0.001 ; p=$ $0.013, p=0.001, p<0.001$; respectively), in men (Table 5). There were no statistically significant differences in terms of HDL-C, $\mathrm{CD}_{3}{ }^{+} \mathrm{KDR}^{+}$and $\mathrm{CD} 34^{+} \mathrm{KDR}^{+} \mathrm{CD}_{133}{ }^{+}$cell number, MMP-9 and VEGF between the age groups in men.
TABLE 2 | Physical characteristics and biochemical and immunological parameters in women according to the three categories of TG-AUC $(n=14)$, mean $\pm \mathrm{SD}$ [min-max].

\begin{tabular}{|c|c|c|c|c|}
\hline $\begin{array}{l}\text { Parameters } \\
\text { TG-AUC } \\
\text { (mg/dl/hour) }\end{array}$ & $\begin{array}{c}\text { Category } 1 \\
\text { low } \\
431.1 \pm 51.2 \\
{[324-523]}\end{array}$ & $\begin{array}{c}\text { Category } 2 \\
\text { intermediate } \\
618.3 \pm 53.5 \\
{[528-694]}\end{array}$ & $\begin{array}{c}\text { Category } 3 \\
\text { high } \\
979.4 \pm 262.2 \\
\text { [722-1639] }\end{array}$ & $\boldsymbol{P}$ \\
\hline Age (years) & $24.8 \pm 7.2$ & $25.4 \pm 9.2$ & $29.2 \pm 10.22$ & 0.266 \\
\hline BMl $\left(\mathrm{kg} / \mathrm{m}^{2}\right)$ & $22.9 \pm 3.4$ & $24.2 \pm 4.8$ & $25.4 \pm 5.9$ & 0.403 \\
\hline Waist/Hip & $0.75 \pm 0.07$ & $0.8 \pm 0.06$ & $0.8 \pm 0.07$ & 0.369 \\
\hline Fat rate (\%) & $25.4 \pm 8.4$ & $26.9 \pm 8.3$ & $28.5 \pm 10.1$ & 0.660 \\
\hline TG (mg/dL) & $50.5 \pm 8.3$ & $69.8 \pm 19.3^{a}$ & $98.1 \pm 28.0^{a, b}$ & $<0.001$ \\
\hline TC (mg/dL) & $166.3 \pm 25.2$ & $158.0 \pm 22.9$ & $197.9 \pm 18.8^{a, b}$ & $<0.001$ \\
\hline LDL-C (mg/dL) & $85.4 \pm 14.3$ & $82.7 \pm 20.4$ & $111.0 \pm 17.7^{a, b}$ & $<0.001$ \\
\hline HDL-C (mg/dL) & $66.1 \pm 15.2$ & $55.4 \pm 8.3$ & $62.6 \pm 11.6$ & 0.066 \\
\hline $\mathrm{CD}_{34}+\mathrm{KDR}^{+}$ & $1.5(0-3)$ & $2.5(2-4)$ & $2(1-3)$ & $0.155^{\star}$ \\
\hline $\begin{array}{l}\mathrm{CD} 34^{+} \mathrm{KDR}^{+} \\
\mathrm{CD}^{+} 33^{+}\end{array}$ & $1(0-2)$ & $2(0-3)$ & $2(1-3)$ & $0.116^{\star}$ \\
\hline VEGF (pg/ml) & $57.5 \pm 24.3$ & $44.5 \pm 14.3$ & $43.4 \pm 21.8$ & 0.146 \\
\hline MMP-9 (ng/ml) & $388.3 \pm 162.4$ & $406.4 \pm 102.9$ & $338.9 \pm 68.3$ & 0.304 \\
\hline
\end{tabular}

P-values according to one-way ANOVA test, post-hoc Tukey's test. Data were expressed as mean $\pm S D$.

${ }^{\star} P$-values according to the Kruskal-Wallis test. Data were expressed as median (interquartile range for $25-75 \%$ ).

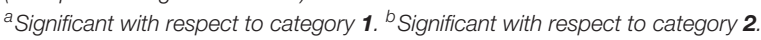

$B M I$, body mass index; $A \cup C$, area under the curve; $C D 34^{+} K D R^{+}$, late endothelial progenitor cell; $C D 34^{+} K D R^{+} C D 133^{+}$, early endothelial progenitor cell.

\section{DISCUSSION}

This study showed that PP hypertriglyceridemia affects the number of EPCs via remnant-like particles in humans following a dietary stressor. Epidemiological studies in recent years have revealed that hypertriglyceridemia is an individual risk factor for CVDs, independent of the other factors (27-30). Since Zilversmit suggested chylomicrons and chylomicron remnants might play a role in atherogenesis (31), many researchers have conducted studies showing the relationship between PP hyperlipidemia and atherosclerotic diseases, especially CVD. It has been shown that remnant lipoprotein particles initiate early atherosclerosis, have adverse effects on endothelial functions, are associated with atherogenic small dense LDL, and also with prothrombotic and proinflammatory biomarkers such as Factor VII, PAI-1, and CRP (31). Because of the frequency of meal ingestion, individuals spend approximately $18 \mathrm{~h}$ in the PP high TG levels. Moreover, the increase in TG levels following a high fat meal has been shown to be associated with an increase of circulating proinflammatory cytokines $(32,33)$.

When the relationship between PP lipemia and lipids and lipoproteins was examined, it was seen that the parameters were higher in men than women. For this reason, these parameters were evaluated separately in the gender categories. Lipid and lipoprotein profiles in the third category exhibited an atherogenic tendency, especially in male subjects. Many studies such as Women's Health Study, Norwegian Counties 
TABLE 3 | Physical characteristics and biochemical and immunological parameters in men according to the three categories of TG-AUC $(n=14)$, mean $\pm \mathrm{SD}$ [min-max].

\begin{tabular}{|c|c|c|c|c|}
\hline $\begin{array}{l}\text { Parameters } \\
\text { TG-AUC } \\
\text { (mg/dl/hour) }\end{array}$ & $\begin{array}{c}\text { Category } 1 \\
\text { low } \\
649.4 \pm 146.8 \\
{[348-887]}\end{array}$ & $\begin{array}{c}\text { Category } 2 \\
\text { intermediate } \\
1068.7 \pm 120.3 \\
{[926-1279]}\end{array}$ & $\begin{array}{c}\text { Category } 3 \\
\text { high } \\
1752.9 \pm 357.7 \\
{[1406-2313]}\end{array}$ & $P$ \\
\hline Age (years) & $27.6 \pm 10.9$ & $35.0 \pm 11.1$ & $40 \pm 9.6^{a}$ & 0.01 \\
\hline BMI $\left(\mathrm{kg} / \mathrm{m}^{2}\right)$ & $24.5 \pm 3.7$ & $28.4 \pm 4.1^{a}$ & $28.9 \pm 3.5^{a}$ & 0.007 \\
\hline Waist/Hip & $0.88 \pm 0.07$ & $0.9 \pm 0.05$ & $0.9 \pm 0.06$ & 0.090 \\
\hline Fat rate (\%) & $16.8 \pm 6.04$ & $27.7 \pm 5.7^{a}$ & $24.1 \pm 5.0^{\mathrm{a}}$ & 0.004 \\
\hline $\mathrm{TG}(\mathrm{mg} / \mathrm{dL})$ & $68.6 \pm 16.5$ & $106.4 \pm 25.9^{a}$ & $179.4 \pm 56.2^{a, b}$ & $<0.001$ \\
\hline TC (mg/dL) & $168.8 \pm 29.6$ & $200.6 \pm 25.3$ & $225.4 \pm 56.9^{a}$ & 0.002 \\
\hline LDL-C (mg/dL) & $97.1 \pm 26.4$ & $129.1 \pm 21.4^{a}$ & $146.1 \pm 47.7^{a}$ & 0.002 \\
\hline HDL-C (mg/dL) & $50.6 \pm 7.5$ & $44.9 \pm 5.7$ & $42.2 \pm 11.5^{\mathrm{a}}$ & 0.039 \\
\hline $\mathrm{CD} 4^{+} \mathrm{KDR}^{+}$ & $1(0-3)$ & $1(0-2)$ & $3(1-7)^{a, b}$ & $0.026^{*}$ \\
\hline $\begin{array}{l}\mathrm{CD} 4^{+} \mathrm{KDR}^{+} \\
\mathrm{CD}^{+} 33^{+}\end{array}$ & $1(0-2)$ & $1(0-2)$ & $3(1-7)^{a, b}$ & $0.015^{*}$ \\
\hline VEGF (pg/ml) & $61.7 \pm 23.8$ & $61.8 \pm 24.5$ & $63.3 \pm 18.3$ & 0.980 \\
\hline MMP-9 (ng/ml) & $423.5 \pm 125.7$ & $481.5 \pm 199.9$ & $345.4 \pm 132.6$ & 0.082 \\
\hline
\end{tabular}

P-values according to one-way ANOVA test, post-hoc Tukey's test. Data were expressed as mean $\pm S D$.

${ }^{*} P$-values according to the Kruskal-Wallis test. Data were expressed as median (interquartile range for $25-75 \%$ ).

a Significant with respect to category $1 .{ }^{b}$ Significant with respect to category 2. $B M I$, body mass index; $A \cup C$, area under the curve; $C D 34^{+} K D R^{+}$, late endothelial progenitor cell; $C D 34^{+} K D R^{+} C D 133^{+}$, early endothelial progenitor cell.

Study, and Copenhagen City Heart Study have shown that there is a strong relationship between cardiovascular events and PP TG levels $(4,7,34)$. In this study, a strong positive correlation between fasting TG levels and TG-AUC values indicates that the PP lipemic response of individuals with high fasting TG levels may also be impaired. In a study by Wojczynski et al., normal and hypertriglyceridemic female and male individuals were compared and LDL-C was found to be significantly higher in hypertriglyceridemic individuals compared to normotriglyceridemic individuals, while HDL-C was found to be significantly lower (35). There was a very strong positive correlation between fasting TG level and TG-AUC values in both sexes in our study. This supports the idea that people with high-fasting TG levels may also have impaired PP lipemic responses. In the study of Kolovou et al., it was found that each $1 \mathrm{mg} / \mathrm{dl}$ increase in fasting TG level caused an increase in TG-AUC value by $8.462 \mathrm{mg} / \mathrm{dl} / \mathrm{h}$, partially supporting findings from our study (36). Remnant lipoproteins are risk factors for endothelial dysfunction and therefore atherosclerosis, and EPCs have a crucial role in vessel wall homeostasis and reduction of atherosclerosis (37-39). According to the "EPC-mediated injury repair" hypothesis (11), we aimed to reveal the relationship between PP lipemia and the number of circulating EPCs. In this study, we showed for the first time the number of EPCs in PP phase. In the literature, there is no in-vivo study on relationship between PP lipemia and EPCs. However, Ferreira et al. showed that PP hyperlipidemia increases the circulating

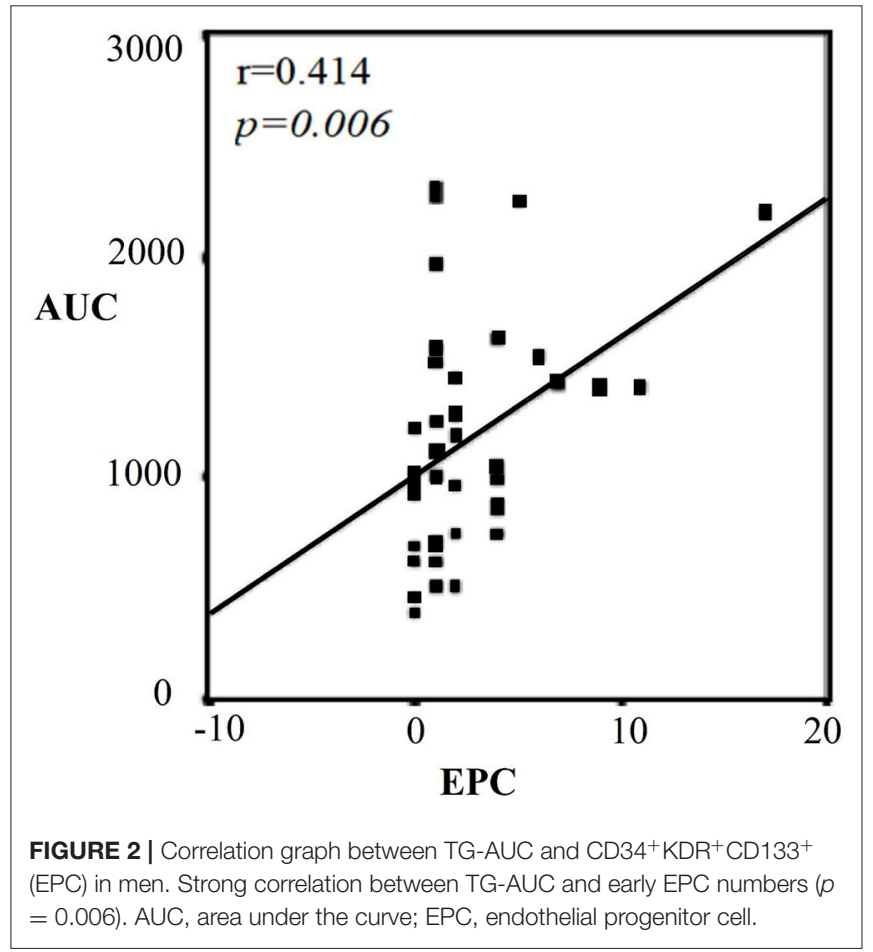

levels of endothelial microparticles (EMPs) (40). In this study, low-fat and high-fat diets were applied to 18 subjects in total. Lipid and EMP levels were measured before and 1 and $3 \mathrm{~h}$ after the meal. By the flow cytometric analysis, it was observed that high-fat meal significantly increased EMP levels after 1 and $3 \mathrm{~h}$ (40). In addition, Liu L. et al. put forward the idea that remnant-like particles may cause atherosclerosis by aging EPCs in 2007, and they published an in vitro study in 2009 (21, 22). It was first noted that remnant-like particles can reduce the adhesion, migration and proliferation capacity of EPCs (22). By the biochemical analyzes, it was observed that the EPCs were aged after treatment with remnant lipoproteins (22). In our study, no statistically significant difference was found in terms of EPC numbers between males and females. There was no statistically significant difference between the category of women. In women, lower and closer PP TG levels, higher HDL-C levels, besides the fact that men have a higher risk of atherosclerosis might explain this situation. Studies have shown that HDL increases the number and activity of EPCs (41-43). Various studies have shown that circulating EPCs are reduced in the presence of classic CVD risk factors (44), non-modifiable risk factors such as age and gender also affect the number of EPCs (45). Accordingly, it has been determined that older people have fewer $\mathrm{CD} 34^{+} \mathrm{KDR}^{+}$ cells than younger people and men have fewer $\mathrm{CD} 34^{+} \mathrm{KDR}^{+}$ cells than women. The number of EPCs may be a factor in explaining the protection of fertile women from CVD risk (45). It can be claimed that the risk of CVD is higher in people with a low EPC count because these people have impaired endothelial repair and compensatory angiogenesis. Hill et al. are the first group to demonstrate a direct correlation between EPC and endothelial function. In their study, endothelial function 
TABLE 4 | Physical characteristics and biochemical and immunological parameters according to the age in women.

\begin{tabular}{|c|c|c|c|}
\hline Parameters & $\begin{array}{l}\text { Young } \\
(n=27)\end{array}$ & $\begin{array}{l}\text { Middle age } \\
\qquad(n=15)\end{array}$ & $P$ \\
\hline Age (years) & $20.9 \pm 3.6$ & $36.4 \pm 6.8$ & $<0.001$ \\
\hline $\mathrm{BMI}\left(\mathrm{kg} / \mathrm{m}^{2}\right)$ & $22.8 \pm 4.5$ & $26.5 \pm 4.8$ & 0.016 \\
\hline $\begin{array}{l}\text { TG-AUC } \\
\text { (mg/dL/hour) }\end{array}$ & $\begin{array}{c}627.6 \pm \\
176.8\end{array}$ & $\begin{array}{c}763.9 \pm \\
391.7\end{array}$ & 0.128 \\
\hline Waist/Hip & $0.7 \pm 0.05$ & $0.8 \pm 0.06$ & $<0.001$ \\
\hline Fat rate (\%) & $24.6 \pm 7.8$ & $31.1 \pm 9.3$ & 0.018 \\
\hline TG (mg/dL) & $72.6 \pm 18.9$ & $73.2 \pm 40.2$ & 0.944 \\
\hline TC (mg/dL) & $168.7 \pm 27.7$ & $183.6 \pm 26.8$ & 0.098 \\
\hline LDL-C (mg/dL) & $87.8 \pm 19.7$ & $102.4 \pm 22.1$ & 0.034 \\
\hline HDL-C (mg/dL) & $61.6 \pm 11.9$ & $60.9 \pm 14.2$ & 0.866 \\
\hline $\mathrm{CD} 34^{+} \mathrm{KDR}^{+}$ & $2(1-4)$ & $2(1-3)$ & $0.229^{*}$ \\
\hline $\mathrm{CD} 4^{+} \mathrm{KDR}^{+} \mathrm{CD} 133^{+}$ & $2(1-3)$ & $2(0-3)$ & $0.637^{*}$ \\
\hline VEGF (pg/ml) & $49.1 \pm 23.1$ & $47.4 \pm 17.7$ & 0.809 \\
\hline MMP-9 (ng/ml) & $382.1 \pm 90.7$ & $\begin{array}{c}370.3 \pm \\
160.4\end{array}$ & 0.760 \\
\hline
\end{tabular}

$P$-values according to the Student's t-test. Data were expressed as mean $\pm S D$.

${ }^{*}$ P-values according to the Mann-Whitney U-test. Data were expressed as median (interquartile range for $25-75 \%$ ).

$B M I$, body mass index; $A \cup C$, area under the curve; $C D 34^{+} K D R^{+}$, late endothelial progenitor cell; $C D 34^{+} K D R^{+} C D 133^{+}$, early endothelial progenitor cell.

was evaluated by flow-mediated dilatation technique (13). Later studies also support this correlation (46-48). In this study, EPC levels of men in the high TG-AUC category were found to be significantly higher than in the intermediate and low TGAUC category. In the high TG-AUC category where the PP TG level is high, the remnant particles remain in circulation for a longer period of time, therefore, susceptibility to atherosclerosis is higher in this category. Based on the literature, it is expected that the number of EPCs in this category, which has a highatherosclerosis susceptibility, is lower than the other groups. In this case, this result we found is different from the literature. However, it has been demonstrated by various studies that the number of EPCs in the circulation increases in acute events such as heart attack and stroke $(37,49,50)$. Therefore, starting from this point, the fact that the number of EPCs increased significantly in the high TG-AUC category brings to mind the situation that develops in response to the existing damage. Despite the fact that the inverse ratio between CVD and EPC number is known, Guven et al. obtained the opposite result in their study; it has been shown that there is a continuous increase in the number of EPCs as the severity of CAD increases (51). When we investigated whether age has an effect on the number of EPCs, it was observed that the number of $\mathrm{CD} 34^{+} \mathrm{KDR}^{+}$cells and $\mathrm{CD}^{2}{ }^{+} \mathrm{KDR}^{+} \mathrm{CD}_{133}{ }^{+}$cells did not change with age. Therefore, the number of EPCs varied according to the PP lipemic response, independently of the age factor.

Shintani et al., in their study, compared patients with acute $\mathrm{MI}$ and the control group in terms of $\mathrm{CD} 34^{+}$mononuclear cells (52). Accordingly, it was observed that $\mathrm{CD} 34^{+}$cells were significantly higher in the acute MI group and the levels of these cultured cells reached the highest point on the $7^{\text {th }}$
TABLE 5 | Physical characteristics and biochemical and immunological parameters according to the age in men.

\begin{tabular}{|c|c|c|c|}
\hline Parameters & Young ( $n=19$ ) & Middle age $(n=23)$ & $\boldsymbol{P}$ \\
\hline Age (years) & $24.3 \pm 3.8$ & $42.8 \pm 8.8$ & $<0.001$ \\
\hline BMI $\left(\mathrm{kg} / \mathrm{m}^{2}\right)$ & $25.4 \pm 4.4$ & $28.8 \pm 3.4$ & 0.007 \\
\hline TG-AUC (mg/dL/hour) & $880.6 \pm 410.1$ & $1385.3 \pm 483.4$ & 0.001 \\
\hline Waist/Hip & $0.9 \pm 0.07$ & $0.9 \pm 0.05$ & 0.002 \\
\hline Fat rate (\%) & $17.7 \pm 6.6$ & $24.1 \pm 4.5$ & 0.001 \\
\hline TG (mg/dL) & $98.1 \pm 56.1$ & $134.7 \pm 57.0$ & 0.043 \\
\hline $\mathrm{TC}(\mathrm{mg} / \mathrm{dL})$ & $173.4 \pm 29.2$ & $218.7 \pm 46.5$ & 0.001 \\
\hline LDL-C (mg/dL) & $102.3 \pm 26.5$ & $142.0 \pm 38.6$ & $<0.001$ \\
\hline HDL-C (mg/dL) & $47.0 \pm 7.7$ & $45.0 \pm 10.2$ & 0.486 \\
\hline $\mathrm{CD}_{3}{ }^{+} \mathrm{KDR}^{+}$ & $1(0-2)$ & $2(1-5)$ & $0.076^{\star}$ \\
\hline $\mathrm{CD} 34^{+} \mathrm{KDR}^{+} \mathrm{CD}_{133^{+}}$ & $1(0-2)$ & $1(1-5)$ & $0.119^{*}$ \\
\hline VEGF (pg/ml) & $63.9 \pm 25.1$ & $60.9 \pm 19.3$ & 0.660 \\
\hline MMP-9 (ng/ml) & $461 \pm 134$ & $380.0 \pm 177.1$ & 0.099 \\
\hline
\end{tabular}

$P$-values according to the Student's t-test. Data were expressed as mean $\pm S D$.

${ }^{*} P$-values according to the Mann-Whitney U-test. Data were expressed as median (interquartile range for $25-75 \%$ ).

$B M I$, body mass index; AUC, area under the curve; $C D 34^{+} K D R^{+}$, late endothelial progenitor cell; $C D 34^{+} K D R^{+} C D 133^{+}$, early endothelial progenitor cell.

day, while there was no change in the control group. In this study, besides $\mathrm{CD}^{+}{ }^{+}$cells, plasma VEGF levels were also measured. VEGF, which is one of the factors that allow EPCs to be delivered from the bone marrow to the circulation, was similarly found to be high in patients with acute MI and reached its highest plasma level on the $7^{\text {th }}$ day. VEGF and MMP-9 levels were also evaluated in our study. According to this while MMP-9 levels are not different between males and females, VEGF levels are higher in males than females and were statistically significant. When the categories of women and men were examined, there was no statistically significant difference between the categories in terms of these parameters. Although VEGF levels in the high TG-AUC category in men were higher than the other two categories, consistent with the EPC numbers, this difference in VEGF levels was not statistically significant.

This study has some limitations: it is an acute, 1-day intervention study providing preliminary evidence requiring confirmation in the long-term intervention studies. Moreover, when we stratified the subjects based on age differences, we compared young age (20.9 years) with middle age (36.4 years), without having older subjects that might provide a better piece of knowledge about aging effect. This last aspect will be investigated with a study aim to understand the effect of aging on EPCs.

In conclusion, we showed that PP hypertriglyceridemia affects the number of EPCs via remnant-like particles in humans following a dietary stressor and that the highest EPC number was found in the high TG-AUC category. Increased EPCs levels in subjects with PP hyperlipidemia may be associated with a response to endothelial injury related to increased atherogenic remnant particles at the $\mathrm{PP}$ phase. Future studies, in a larger number of subjects, are needed to confirm our findings, together 
with an understanding of the association between EPCs, TGAUC, and inflammatory response.

\section{DATA AVAILABILITY STATEMENT}

The raw data supporting the conclusions of this article will be made available by the authors, without undue reservation.

\section{ETHICS STATEMENT}

The studies involving human participants were reviewed and approved by Ethics Committee of Karadeniz Technical

\section{REFERENCES}

1. Hokanson JE, Austin MA. Plasma triglyceride level is a risk factor for cardiovascular disease independent of high-density lipoprotein cholesterol level: A metaanalysis of population-based prospective studies. Eur J Cardiovasc Prevent Rehabilit. (1996) 3:213-9. doi: 10.1177/174182679600300214

2. Grundy SM, Cleeman JI, Bairey Merz CN, Brewer HB, Clark LT, Hunninghake DB, et al. Implications of recent clinical trials for the National Cholesterol Education Program Adult Treatment Panel III guidelines. Circulation. (2004) 110:227-39. doi: 10.1161/01.CIR.0000133317.49796.0E

3. Jackson KG, Poppitt SD, Minihane AM. Postprandial lipemia and cardiovascular disease risk: Interrelationships between dietary, physiological and genetic determinants. Atherosclerosis. (2012) 220:22-33. doi: 10.1016/j.atherosclerosis.2011.08.012

4. Lindman AS, Veierød MB, Tverdal A, Pedersen JI, Selmer R. Nonfasting triglycerides and risk of cardiovascular death in men and women from the Norwegian Counties Study. Eur J Epidemiol. (2010) 25:78998. doi: 10.1007/s10654-010-9501-1

5. Nordestgaard LT, Christoffersen M, Afzal S, Nordestgaard BG, TybjærgHansen A, Frikke-Schmidt R. Triglycerides as a shared risk factor between dementia and atherosclerotic cardiovascular disease: a study of 125,727 individuals. Clin Chem. (2021) 67:245-55. doi: 10.1093/clinchem/hvaa269

6. Patel A. Serum triglycerides as a risk factor for cardiovascular diseases in the Asia-Pacific region. Circulation. (2004) 110:267886. doi: 10.1161/01.CIR.0000145615.33955.83

7. Nordestgaard BG, Benn M, Schnohr P, Tybjaerg-Hansen A. Nonfasting triglycerides and risk of myocardial infarction, ischemic heart disease, and death in men and women. JAMA. (2007) 298:299-308. doi: 10.1001/jama.298.3.299

8. Borén J, Chapman MJ, Krauss RM, Packard CJ, Bentzon JF, Binder CJ, et al. Low-density lipoproteins cause atherosclerotic cardiovascular disease: pathophysiological, genetic, and therapeutic insights: a consensus statement from the European Atherosclerosis Society Consensus Panel. Eur Heart J. (2020) 41:2313-30. doi: 10.1093/eurheartj/ehz962

9. Mudau M, Genis A, Lochner A, Strijdom H. Endothelial dysfunction: The early predictor of atherosclerosis. Cardiovasc J Afr. (2012) 23:22231. doi: 10.5830/CVJA-2011-068

10. Ginsberg HN, Packard CJ, John Chapman M, Borén J, AguilarSalinas CA, Averna M, et al. Triglyceride-rich lipoproteins and their remnants: metabolic insights, role in atherosclerotic cardiovascular disease, and emerging therapeutic strategies-a consensus statement from the European Atherosclerosis Society. Eur Heart J. (2021) 42:4791-806. doi: 10.1093/eurheartj/ehab551

11. Zhang M, Zhou S, Li X, Shen XQ, Fang Z. A novel hypothesis of atherosclerosis: EPCs-mediated repair-to-injury. Med Hypotheses. (2008) 70:838-41. doi: 10.1016/J.MEHY.2007.06.041

12. He S, Guo H, Zhao T, Meng Y, Chen R, Ren J, et al. A defined combination of four active principles from the Danhong injection is necessary and sufficient
University Farabi Hospital. The patients/participants provided their written informed consent to participate in this study.

\section{AUTHOR CONTRIBUTIONS}

All authors listed have made a substantial, direct, and intellectual contribution to the work and approved it for publication.

\section{FUNDING}

This project was funded by the Karadeniz Technical University Research Fund (Project Number: 2010.114.001).

to accelerate EPC-mediated vascular repair and local angiogenesis. Front Pharmacol. (2019) 10:1080. doi: 10.3389/FPHAR.2019.01080/BIBTEX

13. Hill JM, Zalos G, Halcox JPJ, Schenke WH, Waclawiw MA, Quyyumi AA, et al. Circulating endothelial progenitor cells, vascular function, and cardiovascular risk. N Engl J Med. (2003) 348:593-600. doi: 10.1056/NEJMOA022287

14. Takahashi T, Kalka C, Masuda H, Chen D, Silver M, Kearney M, et al. Ischemia- and cytokine-induced mobilization of bone marrow-derived endothelial progenitor cells for neovascularization. Nat Med. (1999) 5:4348. doi: $10.1038 / 7434$

15. Asahara T, Murohara T, Sullivan A, Silver M, van der Zee R, Li T, et al. Isolation of putative progenitor endothelial cells for angiogenesis. Science. (1997) 275:964-7. doi: 10.1126/SCIENCE.275.5302.964

16. Johnson KE, Wilgus TA. Vascular endothelial growth factor and angiogenesis in the regulation of cutaneous wound repair. Adv Wound Care. (2014) 3:647. doi: 10.1089/WOUND.2013.0517

17. Cesari F, Gori AM, Romagnuolo I, Abbate R. [Endothelial progenitor cells and vascular health: effects of lifestyle's modifications]. Monaldi Arch Chest Dis. (2012) 78:66-72. doi: 10.4081/MONALDI.2012.125

18. Li YF, Ren LN, Guo G, Cannella LA, Chernaya V, Samuel $S$, et al. Endothelial progenitor cells in ischemic stroke: An exploration from hypothesis to therapy. J Hematol Oncol. (2015) 8:1-17. doi: 10.1186/S13045-015-0130-8/FIGURES/8

19. Wu Y, Ip JE, Huang J, Zhang L, Matsushita K, Liew CC, et al. Essential role of ICAM-1/CD18 in mediating EPC recruitment, angiogenesis, and repair to the infarcted myocardium. Circulation Res. (2006) 99:31522. doi: 10.1161/01.RES.0000235986.35957.A3

20. Fadini GP, Agostini C, Sartore S, Avogaro A. Endothelial progenitor cells in the natural history of atherosclerosis. Atherosclerosis. (2007) 194:4654. doi: 10.1016/j.atherosclerosis.2007.03.046

21. Pu DR, Liu L. Remnant like particles may induce atherosclerosis via accelerating endothelial progenitor cells senescence. Med Hypotheses. (2007) 69:293-6. doi: 10.1016/j.mehy.2006.11.046

22. Liu L, Wen T, Zheng X, Yang DG, Zhao SP, Xu DY, et al. Remnant-like particles accelerate endothelial progenitor cells senescence and induce cellular dysfunction via an oxidative mechanism. Atherosclerosis. (2009) 202:40514. doi: 10.1016/j.atherosclerosis.2008.05.024

23. Chopra H, Hung MK, Kwong DL, Zhang CF, Pow EHN. Insights into endothelial progenitor cells: Origin, classification, potentials, and prospects. Stem Cells Int. (2018) 2018:47015. doi: 10.1155/2018/9847015

24. Yang D, Liu L, Zhou S, Ma M, Wen T. Remnant-like lipoproteins may accelerate endothelial progenitor cells senescence through inhibiting telomerase activity via the reactive oxygen species-dependent pathway. Canad J Cardiol. (2011) 27:628-34. doi: 10.1016/J.CJCA.2010.12.075

25. Cortés B, Núñez I, Cofán M, Gilabert R, Pérez-Heras A, Casals E, et al. Acute effects of high-fat meals enriched with walnuts or olive oil on postprandial endothelial function. J Am College Cardiol. (2006) 48:166671. doi: 10.1016/j.jacc.2006.06.057

26. Patsch JR, Miesenbock G, Hopferwieser T, Muhlberger V, Knapp E, Dunn $\mathrm{JK}$, et al. Relation of triglyceride-metabolism and coronary-artery disease - 
studies in the postprandial state. Arteriosclerosis Thrombosis. (1992) 12:133645. doi: 10.1161/01.Atv.12.11.1336

27. Wilson PWF, Meigs JB. Cardiometabolic risk: a Framingham perspective. Int J Obesity. (2005) 32(Suppl. 2):S17-20. doi: 10.1038/IJO.2008.30

28. Toth PP, Shah PK, Lepor NE. Targeting hypertriglyceridemia to mitigate cardiovascular risk: A review. Am J Prevent Cardiol. (2020) 3:100086. doi: 10.1016/J.AJPC.2020.100086

29. Nakajima K, Tanaka A. Atherogenic postprandial remnant lipoproteins; VLDL remnants as a causal factor in atherosclerosis. Clinica Chimica Acta. (2018) 478:200-215. doi: 10.1016/J.CCA.2017.12.039

30. Kats D, Sharrett A, Ginsberg H. Postprandial Lipemia and the Risk of Coronary Heart Disease and Stroke: The Atherosclerosis Risk in Communities (ARIC) Study. drc.bmj.com https://drc.bmj.com/content/5/1/e000335.abstract (accessed December 15, 2021).

31. Zilversmit DB. Atherogenesis: A postprandial phenomenon. Circulation. (1979) 60:473-85. doi: 10.1161/01.CIR.60.3.473

32. Peluso I, Villano D, Roberts S, Cesqui E, Raguzzini A, Borges $\mathrm{G}$, et al. Consumption of mixed fruit-juice drink and vitamin $\mathrm{C}$ reduces postprandial stress induced by a high fat meal in healthy overweight subjects. Curr Pharmaceut Design. (2014) 20:1020-4. doi: 10.2174/138161282006140220144802

33. Miglio C, Peluso I, Raguzzini A, Villaño D, Cesqui E, Catasta $\mathrm{G}$, et al. Antioxidant and inflammatory response following highfat meal consumption in overweight subjects. Eur J Nutr. (2013) 52:1107-14. doi: 10.1007/S00394-012-0420-7

34. Bansal S, Buring JE, Rifai N, Mora S, Sacks FM, Ridker PM. Fasting compared with nonfasting triglycerides and risk of cardiovascular events in women. $J$ Am Med Assoc. (2007) 298:309-16. doi: 10.1001/jama.298.3.309

35. Wojczynski MK, Glasser SP, Oberman A, Kabagambe EK, Hopkins PN, Tsai MY, et al. High-fat meal effect on LDL, HDL, and VLDL particle size and number in the Genetics of Lipid-Lowering drugs and diet network (GOLDN): An interventional study. Lipids Health Dis. (2011) 10:111. doi: 10.1186/1476-511X-10-181/FIGURES/6

36. Kolovou GD, Anagnostopoulou KK, Pavlidis AN, Salpea KD, Iraklianou $\mathrm{SA}$, Tsarpalis $\mathrm{K}$, et al. Postprandial lipemia in men with metabolic syndrome, hypertensives and healthy subjects. Lipids Health Dis. (2005) 4:1-8. doi: 10.1186/1476-511X-4-21/FIGURES/2

37. Qian S, You S, Sun Y, Wu Q, Wang X, Tang W, et al. Remnant cholesterol and common carotid artery intima-media thickness in patients with ischemic stroke. Circulation Cardiovasc imaging. (2021) 14:32535. doi: 10.1161/CIRCIMAGING.120.010953

38. Levin MG. Remnant lipoproteins as a target for atherosclerosis risk reduction. Arteriosclerosis Thrombosis Vasc Biol. (2021) 41:2076-9. doi: 10.1161/ATVBAHA.121.316341

39. Duran EK, Pradhan AD. Triglyceride-rich lipoprotein remnants and cardiovascular disease. Clin Chem. (2021) 67:18396. doi: 10.1093/CLINCHEM/HVAA296

40. Ferreira AC, Peter AA, Mendez AJ, Jimenez JJ, Mauro LM, Chirinos JA, et al. Postprandial hypertriglyceridemia increases circulating levels of endothelial cell microparticles. Circulation. (2004) 110:3599-603. doi: 10.1161/01.CIR.0000148820.55611.6B

41. Itzhaki Ben Zadok O, Mager A, Leshem-Lev D, Lev E, Kornowski R, Eisen A. The effect of proprotein convertase subtilisin kexin type 9 inhibitors on circulating endothelial progenitor cells in patients with cardiovascular disease. Cardiovas Drugs Ther. (2021) 2021:1-8. doi: 10.1007/S10557-020-07119-1/FIGURES/4

42. Pu DR, Liu L. HDL slowing down endothelial progenitor cells senescence: A novel anti-atherogenic property of HDL. Med Hypotheses. (2008) 70:33842. doi: 10.1016/J.MEHY.2007.05.025
43. Tso C, Martinic G, Fan WH, Rogers C, Rye KA, Barter PJ. Highdensity lipoproteins enhance progenitor-mediated endothelium repair in mice. Arteriosclerosis Thrombosis Vasc Biol. (2006) 26:1144-9. doi: 10.1161/01.ATV.0000216600.37436.cf

44. Möbius-Winkler S, Höllriegel R, Schuler G, Adams V. Endothelial progenitor cells: implications for cardiovascular disease. Cytometry Part A. (2009) 75:2537. doi: 10.1002/CYTO.A.20669

45. Ren Z, Guo J, Xiao X, Huang J, Li M, Cai R, et al. The effect of sex differences on endothelial function and circulating endothelial progenitor cells in hypertriglyceridemia. Cardiol Res Pract. (2020) 2020:2132918. doi: 10.1155/2020/2132918

46. Loiola RA, García-Gabilondo M, Grayston A, Bugno P, Kowalska A, Duban-Deweer S, et al. Secretome of endothelial progenitor cells from stroke patients promotes endothelial barrier tightness and protects against hypoxia-induced vascular leakage. Stem Cell Res Ther. (2021) 12:123. doi: $10.1186 / S 13287-021-02608-Y$

47. Li X, Chen C, Wei L, Li Q, Niu X, Xu Y, et al. Exosomes derived from endothelial progenitor cells attenuate vascular repair and accelerate reendothelialization by enhancing endothelial function. Cytotherapy. (2016) 18:253-62. doi: 10.1016/J.JCYT.2015.11.009

48. Calò LA, Facco M, Davis PA, Pagnin E, Maso LD, Puato M, et al. Endothelial progenitor cells relationships with clinical and biochemical factors in a human model of blunted angiotensin II signaling. Hyperten Res. (2011) 34:101722. doi: $10.1038 / \mathrm{hr} .2011 .72$

49. Regueiro A, Cuadrado-Godia E, Bueno-Betí C, Diaz-Ricart M, Oliveras A, Novella S, et al. Mobilization of endothelial progenitor cells in acute cardiovascular events in the PROCELL study: Time-course after acute myocardial infarction and stroke. J Mol Cell Cardiol. (2015) 80:14655. doi: 10.1016/J.YJMCC.2015.01.005

50. Massa M, Rosti V, Ferrario M, Campanelli R, Ramajoli I, Rosso R, et al. Increased circulating hematopoietic and endothelial progenitor cells in the early phase of acute myocardial infarction. Blood. (2005) 105:199206. doi: 10.1182/BLOOD-2004-05-1831

51. Güven H, Shepherd RM, Bach RG, Capoccia BJ, Link DC. The number of endothelial progenitor cell colonies in the blood is increased in patients with angiographically significant coronary artery disease. J Am College Cardiol. (2006) 48:1579-87. doi: 10.1016/J.JACC.2006.04.101

52. Shintani S, Murohara T, Ikeda H, Ueno T, Honma $\mathrm{T}$, Katoh A, et al. Mobilization of endothelial progenitor cells in patients with acute myocardial infarction. Circulation. (2001) 103:2776-9. doi: 10.1161/HC2301.092122

Conflict of Interest: The authors declare that the research was conducted in the absence of any commercial or financial relationships that could be construed as a potential conflict of interest.

Publisher's Note: All claims expressed in this article are solely those of the authors and do not necessarily represent those of their affiliated organizations, or those of the publisher, the editors and the reviewers. Any product that may be evaluated in this article, or claim that may be made by its manufacturer, is not guaranteed or endorsed by the publisher.

Copyright (๑) 2022 Akcan, Örem, Altinkaynak, Kural, Örem, Sönmez and Serafini. This is an open-access article distributed under the terms of the Creative Commons Attribution License (CC BY). The use, distribution or reproduction in other forums is permitted, provided the original author(s) and the copyright owner(s) are credited and that the original publication in this journal is cited, in accordance with accepted academic practice. No use, distribution or reproduction is permitted which does not comply with these terms. 